\title{
Investigation of stress-strain state in the flywheel and estimation their specific energy capacity
}

\author{
Dmitri V. Berezhnoi ${ }^{1, *}$, Lejsan R. Gajnulina ${ }^{1}$, and Andrej A. Sachenkov ${ }^{1}$ \\ ${ }^{1}$ Kazan (Volga Region) Federal University, 18 Kremlyovskaya Street, Kazan, 420008, Russian Federation
}

\begin{abstract}
In this paper, the specific energy intensity of the kinetic energy storage devices, including the flywheel-casing scheme in the potential field, is investigated. The possibilities of using various structural materials in the manufacture of structural elements of a mechanical accumulator are analyzed, the stressstrain state of the flywheel and the casing under quasistatic increase in the rotational speed of the rotor part of the structure is investigated. It is noted that the presence of a potential field in the flywheel-casing system makes it possible to increase the specific energy intensity of the kinetic energy storage.
\end{abstract}

\section{Introduction}

Recently, the problem of accumulation and conservation of energy has become increasingly important. The creation of new materials allows not only to improve the existing traditional electrochemical batteries, but also to seek new methods of accumulating and storing energy, including mechanical ones. Mechanical so-called "static" and "dynamic" mechanical energy storage devices can be referred to mechanical energy storage devices.

Static battery stores stored energy in static, in a stationary state. But these batteries have a very small accumulated specific energy. Contrary to this static batteries have provided a solid place in many machines and mechanisms, since they possess such properties high efficiency, stability of accumulated energy and durability. Simple enough is the technology of energy storage by means of kinetic storage. The flywheel battery is promising because, firstly, flywheels are capable of instantly gaining colossal power; Secondly, they are very reliable, long-lasting, economical (the flywheel has a high coefficient of efficiency, the only one of the batteries capable of using mechanical energy on the descents and braking the vehicles on which they can be used with great efficiency); Thirdly, they are environmentally safe, which in our time is very important. The main limitation in implementing such a technology is the rotational speed of the rotor part of the kinetic storage, which can lead to an increase in the stress level and its possible further destruction. An essential factor determining the specific energy intensity of kinetic energy stores is the ratio of the ultimate destructive stress to the density of the material, which, together with the safety requirements, dictates the use of super flywheels (flywheels made by winding threads or tapes).

For flywheels of arbitrary shape, numerical methods for studying the specific kinetic energy are proposed in the literature [1-9]. In a number of works kinetic energy storage devices made of rubber-like materials are proposed, for the calculation of which special methods are proposed [10-14]. The calculation of superflywheels, made by winding threads or tapes, presupposes methods for their contact interaction [1522].

In this paper, we present some results of estimating the specific power consumption of flywheels, including kinetic and potential deformation energy, an algorithm for calculating the stress-strain state and specific energy for flywheels of various shapes and structures.

\section{Formulation of the problem}

One of the most important indicators of the efficiency of the energy storage device is the specific energy intensity, i.e. The ratio of accumulated energy to mass. Formulas for calculating the specific energy intensity for the kinetic bodies of the simplest form have long been known and are given in many sources, but estimates of the specific energy intensity for potential energy are much less common in the literature. In particular, for a flywheel in the form of a disk with a hole [23, 24], an estimate of the specific energy intensity with respect to the kinetic energy can be written in the form

$$
K_{\mathrm{m}}=\left(\sigma_{\mathrm{y}}\left(1+k^{2}\right)\right) /\left(\rho\left(3+\mu+(1-\mu) k^{2}\right)\right),
$$

where $\sigma_{\mathrm{y}}$ and $\mu$ are the time resistance and the Poisson's ratio of the flywheel material, $k$ is the ratio of the inner radius of the flywheel to the outer one. An estimate of the specific energy intensity from the potential energy of deformation obtained under the condition that the flywheel is in a plane-stressed state can be written in the form

$$
P_{\mathrm{m}}=\alpha\left(\sigma_{\mathrm{y}}\right)^{2} /\left(6 E \rho\left(3+\mu+(1-\mu) k^{2}\right)\right)
$$

\footnotetext{
*Corresponding author: berezhnoi.dmitri@mail.ru
} 
where

$$
\left.\alpha=\left(1+k^{4}\right)\left(7-6 \mu+\mu^{2}\right)+2 k^{2}\right)\left(17+6 \mu+\mu^{2}\right),
$$

and $E$ is the Young's modulus of the flywheel material. It can be noted that for flywheels made of rubber-like materials, the energy capacity estimate for the potential energy of deformation is much higher than in kinetic energy.

In the framework of the solution of a geometrically nonlinear problem [25-29], the components of the Cauchy-Green tensor are used in the deformation ratio. The global scheme for solving the problem with allowance for geometric nonlinearity is as follows. The general variational equation for the total potential energy is written:

$$
\delta W+\delta W_{\mathrm{g}}=0,
$$

where part $\delta W$ refers to the whole structure, part $\delta W_{\mathrm{g}}$ describes geometrically nonlinear deformation. Further, within the framework of the finite element method, the global rigidity matrix is assembled, after assembly of which the variational equation takes the form:

$$
\{\delta q\}^{\mathrm{T}}\left(\{R\}+\left\{R_{\mathrm{g}}\right\}\right)=0,
$$

where $\{\delta q\}$ is the variation of the vector of nodal displacements, $\{R\}$ and $\left\{R_{\mathrm{g}}\right\}$ - vectors of generalized forces. As a result, the Newton method for the vector function $F$ :

$$
F=F(\{q\})=\{R\}+\left\{R_{\mathrm{g}}\right\} .
$$

Accordingly, giving the initial approximation $\left(\{q\}^{(0)}\right)$, we construct an iterative procedure:

$$
\begin{gathered}
\{\Delta q\}=-F_{\mathrm{u}}(\{q\})^{-1} F(\{q\}), \\
\{q\}^{(\mathrm{n}+1)}=\{q\}^{(\mathrm{n})}+\{\Delta q\}^{(\mathrm{n})} . \\
F_{\mathrm{q}}=d F_{\mathrm{u}} / d\{q\} .
\end{gathered}
$$

The transition from the variational problem to the algebraic one is done by means of discretization by the finite element method. The relationship between stresses and strains is determined by the well-known Green formula

$$
\sigma_{\mathrm{ij}}=\partial U / \partial \varepsilon_{\mathrm{ij}} .
$$

In the case of a linearly elastic material, the elastic potential is taken in the form

$$
U=C_{\mathrm{ijkl}} \varepsilon_{\mathrm{ij}} \varepsilon_{\mathrm{kl}} / 2,
$$

where $C_{\mathrm{ijk}}$ are the coefficients of the isothermal elasticity tensor. To study the stress-strain state of flywheels made of elastomers, we will use the MooneyRivlin potential in the form

$$
U=C_{10}\left(I_{1}-3\right)+C_{01}\left(I_{2}-3\right)+(J-1)^{2} / d,
$$

where $C_{10}, C_{01}$ are the coefficients of the model, material constants; $I_{1}$ and $I_{2}$ are the invariants of the deviator of deformation; $J$ - determinant of the strain gradient matrix; $d$ is the coefficient of incompressibility of the material. In the subsequent calculation, the Mooney-Rivlin constants for ordinary rubber $C_{10}=0.293$, $C_{01}=0.177$ and the material incompressibility coefficient $d=0.0042$ were used.

Specific energy intensities for flywheel in the form of a disk with a hole, obtained for a number of materials, whose mechanical characteristics are given in Table 1, are presented in Table 2 .

Table 1. Mechanical characteristics of a number of materials used in the manufacture of flywheels.

\begin{tabular}{|c|c|c|c|c|}
\hline Materials & $\begin{array}{c}\text { Young's } \\
\text { modulus } \\
{[\mathbf{M P a}]}\end{array}$ & $\begin{array}{c}\text { Poiss } \\
\text { on's } \\
\text { ratio }\end{array}$ & $\begin{array}{c}\text { Yield } \\
\text { stress } \\
{[\mathbf{M P a}]}\end{array}$ & $\begin{array}{c}\text { Density } \\
{\left[\mathbf{k g} / \mathbf{m}^{\mathbf{3}}\right]}\end{array}$ \\
\hline $\begin{array}{c}\text { High } \\
\text { carbon } \\
\text { steels }\end{array}$ & 215000 & 00.3 & 1155 & 7900 \\
\hline $\begin{array}{c}\text { Titanium } \\
\text { alloys }\end{array}$ & 120000 & 0.3 & 1245 & 4800 \\
\hline $\begin{array}{c}\text { Boron } \\
\text { carbide }\end{array}$ & 472 & 0.3 & 5687 & 2550 \\
\hline $\begin{array}{c}\text { Composites } \\
\text { polymer } \\
\text { CFRP }\end{array}$ & 150000 & 0.25 & 1050 & 1600 \\
\hline $\begin{array}{c}\text { Polyuretha } \\
\text { ne } \\
\text { elastomers } \\
\text { (eiPU) }\end{array}$ & 3 & 0.48 & 51 & 1250 \\
\hline $\begin{array}{c}\text { Kevlar } \\
\text { aramid } \\
\text { fiber 49 }\end{array}$ & 170000 & 0.36 & 3600 & 1440 \\
\hline
\end{tabular}

Table 2. Specific energy capacyty of the flywheel $[\mathrm{MJ} / \mathrm{kg}]$ over the potential $(P \mathrm{~m})$ and kinetic $(\mathrm{Km})$ energies for the thin ring $(k=1)$.

\begin{tabular}{|c|c|c|}
\hline Materials & $P_{\mathrm{m}}$ & $K_{\mathrm{m}}$ \\
\hline High carbon steels & 0.0004 & 0.073 \\
\hline Titanium alloys & 0.0013 & 0.129 \\
\hline Boron carbide & 0.0134 & 1.115 \\
\hline $\begin{array}{c}\text { Composites polymer } \\
\text { CFRP }\end{array}$ & 0.0023 & 0.328 \\
\hline $\begin{array}{c}\text { Polyurethane } \\
\text { elastomers (eiPU) }\end{array}$ & 0.3470 & 0.020 \\
\hline
\end{tabular}

\section{Numerical results}

Of the potential fields used in engineering, namely gravitational, electrostatic and magnetic, in the flywheelhull system, the latter can be applied. The use of potential coupling in the mutual repulsion mode allows to unload the outer layers of the flywheel by transferring the load to the body and thus increasing the speed of rotation of the flywheel and the stored energy. Also, due to the inclusion in the work of the body of the kinetic energy storage device, which is in a compressed state due to the difference in internal and external atmospheric pressure, it is possible to reduce its weight by removing 
the load by the amount created by the potential field and to change the sign of the load from compression to tension, More preferably for modern synthetic materials. To create a magnetic unloading of the outer layers of the flywheel rotor, it is necessary to use a magnetic material, which makes it possible to create repulsive forces between the flywheel rotor and the sturdy body of the magnetic energy store.

When winding the flywheel rim from the magnetized tape, the entire flywheel acquires the properties of a magnet with radial magnetization, with each subsequent winding coil being attracted to the previous one, and, consequently, to the body of the flywheel. The attraction of the subsequent turns prevents the flywheel from breaking off, which occurs at high rotational speeds. The magnetic body is made by winding with a magnetic tape (used earlier for winding the flywheel rim), but with counter magnetization. Under the influence of magnetic forces, the flywheel rim will be repelled by the body magnet. Unloading the rim of the flywheel with the transmission of the centrifugal forces arising and striving to destroy the flywheel on the body of the mechanical energy storage allows substantially increasing the speed of rotation of the flywheel without destroying it.

Consider the simplest axisymmetric mechanical model of the flywheel-casing system (Fig. 1). The flywheel rotates at a constant angular velocity $\omega$ inside the casing, a constant potential field acts between the casing and flywheel, which (in the first approximation) generates an excess pressure $q$ in the gap between the flywheel and the casing. The internal radius of the flywheel $r 0$, outer $-r 1$, the size of the clearance between the flywheel and the casing - $t$, the inner radius of the casing $r 2$, outer $-r 3$. The density and time resistance of the material of the flywheel are respectively $\rho_{\mathrm{m}}$ and $\sigma_{\mathrm{ym}}$, the shell materials are $\rho_{\mathrm{k}}$ and $\sigma_{\mathrm{yk}}$, respectively. In this case, the solution obtained does not depend on the rotation angle $\varphi$, but depends only on the current radius $r$ of the disk.

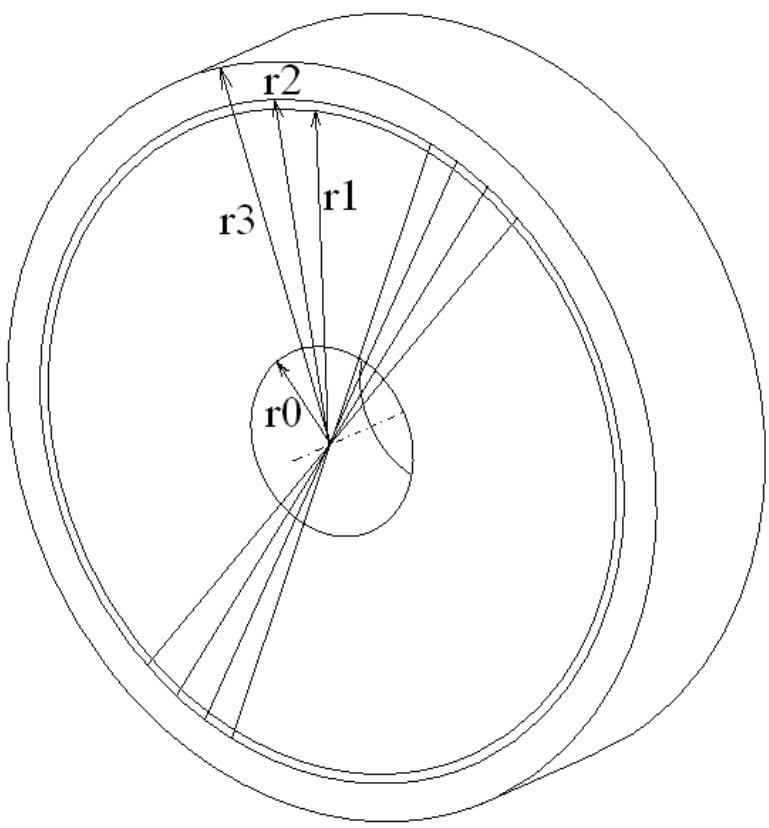

Fig. 1. Model of flywheel-housing system.
Two types of calculations were carried out (for a flywheel without a casing, for a flywheel with a casing in a potential field, in a potential field) to estimate the specific energy intensity of some structural materials whose mechanical characteristics are given in Table 1 . Table 3 gives the specific energy intensities of flywheels and flywheels with housings from the boron carbide in the potential field (for kinetic energy $\mathrm{Km}$ ). Table 4 gives the specific energy intensities of flywheels and flywheels with casing from the kevlar aramid fiber 49.

Table 3. Specific energy consumption of flywheels in the form of discs without a hole $[\mathrm{MJ} / \mathrm{kg}]$ with a casing of the boron carbide and without it in kinetic $(\mathrm{Km})$ energy.

\begin{tabular}{|c|c|c|}
\hline Materials & $\begin{array}{c}\text { Flywheel } \\
\text { scheme }\end{array}$ & $\begin{array}{c}\text { Flywheel- } \\
\text { casing } \\
\text { scheme }\end{array}$ \\
\hline High carbon steels & 0.071 & 0.889 \\
\hline Titanium alloys & 0.13 & 0.871 \\
\hline Boron carbide & 0.33 & 0.909 \\
\hline $\begin{array}{c}\text { Composites polymer } \\
\text { CFRP }\end{array}$ & 0.020 & 1.105 \\
\hline $\begin{array}{c}\text { Polyurethane elastomers } \\
\text { (eiPU) }\end{array}$ & 1.25 & 0.409 \\
\hline
\end{tabular}

Table 4. Specific energy consumption of flywheels in the form of discs without a hole $[\mathrm{MJ} / \mathrm{kg}]$ with a casing of the Kevlar aramid fiber 49 and without it in kinetic (Km) energy.

\begin{tabular}{|c|c|c|}
\hline Materials & $\begin{array}{c}\text { Flywheel } \\
\text { scheme }\end{array}$ & $\begin{array}{c}\text { Flywheel- } \\
\text { casing } \\
\text { scheme }\end{array}$ \\
\hline High carbon steels & 0.073 & 0.849 \\
\hline Titanium alloys & 0.13 & 0.818 \\
\hline Boron carbide & 0.328 & 0.885 \\
\hline $\begin{array}{c}\text { Composites polymer } \\
\text { CFRP }\end{array}$ & 0.020 & 1.232 \\
\hline $\begin{array}{c}\text { Polyurethane elastomers } \\
\text { (eiPU) }\end{array}$ & 1.25 & 0.409 \\
\hline
\end{tabular}

\section{Analysis of results and conclusions}

In conclusion, it should be noted that a comparative analysis of the specific power consumption of flywheels (only the kinetic energy of rotation was estimated) with a casing and without it was carried out. It can be noted that when using the flywheel-casing system in the potential field, the specific strength of the casing material and $\sigma_{\mathrm{yk}} / \rho_{\mathrm{k}}$ should be higher than the specific strength of flywheel material $\sigma_{\mathrm{ym}} / \rho_{\mathrm{m}}$. The presence of a potential field in the flywheel-casing system makes it possible to increase the specific energy intensity for flywheels. The presence of additional winding threads that enhance the power structure of the housing reduces the specific energy intensity of the kinetic energy storage. 
The flywheel was considered only as a disk with a hole, but the results can be generalized also to the case of a flywheel in the form of a solid disk. Generally speaking, at high speeds of rotation of a flywheel presence of a casing is obligatory, since In the immediate vicinity of the rotating part of the structure it is necessary to create a vacuum, so taking into account the mass of the casing when calculating the specific energy intensity is mandatory. The presence of a potential field between the flywheel and the casing makes it possible to increase the angular speed of rotation of the flywheel, but we can not increase the infinitely angular velocity, because Thus the mass of the casing begins to grow.

The calculations show that the involvement of not only the flywheel with the geometric and physicalmechanical parameters given in the work, but also the case of the flywheel energy storage, increases the flywheel rotation speed by 1.4 times. Thus, the specific energy intensity of the flywheel energy storage can be increased more than 2 times.

The reported study was supported by RFBR and Government of the Republic of Tatarstan research projects No. 15-4102555, 15-41-02557.

\section{References}

1. T.O. Drum, Energy storage-flywheel, http:// www.resilience.org/stories/2011-10-05/energystorage-flywheel.

2. N.V. Gulia, Machovichnye dvigately (Mashinostroenie, Moskva, 1976) 163 (In Russian).

3. N.V. Gulia, Nakopitely Energii (Nauka, Moskva, 1980) 152 (In Russian).

4. V.V. Matveev, G.V. Pisarenko, A.P. Yakovlev, Spravochnik po soprotivleniyu materialov on resistance of materials (Naukova Dumka, Kiev, 1988) 736 (In Russian).

5. Y. Seong-yeol, L. Wook-ryun, B. Yong-chae, N. Myounggyu, Journal of Mechanical Science and Technology 24, 231-235 (2010)

6. D.V. Berezhnoi, D.E. Chickrin, A.F. Galimov, Applied Mathematical Sciences 8 (124), 6181-6190 (2014)

7. D.V. Berezhnoi, D.E. Chickrin, E.Yu. Kurchatov, A.F. Galimov, Applied Mathematical Sciences 8 (163), 8125-8135 (2014)

8. D.V. Berezhnoi, D.E. Chickrin, L.R. Gajnulina, E.Yu. Kurchatov, P.A. Kokunin, I.G. Sozutov, M.I. Shigapov, Contemporary Engineering Sciences 8 (36), 1703-1712 (2015)

9. D.V. Berezhnoy, L.R. Gajnulina, L.R. Sekaeva, International Journal of Applied Engineering Research 10 (24), 44672-44676 (2015)

10. A.I. Abdrakhmanova, L.U. Sultanov, Materials Physics and Mechanics 26 (1), 30-32 (2016)

11. A.I. Golovanov, L.U. Sultanov, International Applied Mechanics 41 (6), 614-620 (2005)
12. R.L. Davydov, L.U. Sultanov, Journal of Engineering Physics and Thermophysics 88 (5), 1280-1288 (2015)

13. L.U. Sultanov, L.R. Fakhrutdinov, Magazine of Civil Engineering 44 (9), 69-74 (2013)

14. L.U. Sultanov, R.L. Davydov, Magazine of Civil Engineering 44 (9), 64-68 (2013)

15. O. Sachenkov, L. Kharislamova, N. Shamsutdinova, E. Kirillova, Yu. Konoplev, IOP Conference Series: Materials Science and Engineering 98, 012015 (2015)

16. O. Sachenkov, R. Hasanov, P. Andreev, Y. Konoplev, IOP Conference Series: Materials Science and Engineering 158 (1), 012079 (2016)

17. F.A. Shigapova, R.F. Mustakimova, G.T. Saleeva, O.A. Sachenkov, International Journal of Applied Engineering Research 10 (24), 44711-44714 (2015)

18. O.A. Sachenkov, V.I. Mitryaikin, T.A. Zaitseva, Yu.G. Konoplev, Applied Mathematical Sciences 8 (159), 7889-7897 (2014)

19. I.B. Badriev, V.V. Banderov, M.V. Makarov, V.N. Paimushin, Applied Mathematical Sciences 9 (78), 3887-3895 (2015)

20. I.B. Badriev, V.V. Banderov,O.A. Zadvornov, Applied Mechanics and Materials 392, 188-190 (2013)

21. I.B. Badriev, G.Z. Garipova, M.V. Makarov, V.N. Paimushin, Research Journal of Applied Sciences 10 (8), 428-435 (2015)

22. Y.N. Rabotnov, Soprotivlenye materialov (Fizmatgiz, Moskva, 1962) 456 (In Russian).

23. D.V. Berezhnoi, L.R. Gajnulina, IOP Conference Series: Materials Science and Engineering 158 (1), 012017 (2016)

24. D.V. Berezhnoi, D.E. Chickrin, L.R. Gajnulina, E.Yu. Kurchatov, P.A. Kokunin, I.G. Sozutov, M.I. Shigapov, Contemporary Engineering Sciences 9 (32), 1591-1598 (2016)

25. D. Kolarov, A. Baltov, N. Boncheva, Mechanics of plastic mediums (Mir, Moscow, 1979), 302 (In Russian).

26. A.S. Sakharov, V.N. Kislooky, V.V. Kirichevski, N. Altenbach, U. Gabbert, Y. Dankert, Kh. Kepler, Z. Kochyk, The finite element method in the mechanics of solids (Higher School, Kiev, 1982), 480 (In Russian).

27. P.V. Trusov, A.I. Shveikin, The theory of constitutive relations, (Perm State Technical University, Perm, 2008), 243 (In Russian).

28. V.I. Levitas, The large elastic-plastic deformation of materials under high pressure (Naukova Dumka, Kiev, 1987), 232 (In Russian).

29. A.A. Pozdeev, P.V. Trusov, Y.I. Nyashin, The large elastic-plastic deformation theory, algorithm, application (Nauka, Moscow, 1986), 232 (In Russian). 